\title{
Downregulation of the Taurine Transporter TauT During Hypo-Osmotic Stress in NIH3T3 Mouse Fibroblasts
}

\author{
Daniel Bloch Hansen • Martin Barfred Friis • \\ Else Kay Hoffmann • Ian Henry Lambert
}

Received: 8 July 2011/ Accepted: 26 January 2012/Published online: 2 March 2012

(c) The Author(s) 2012. This article is published with open access at Springerlink.com

\begin{abstract}
The present work was initiated to investigate regulation of the taurine transporter TauT by reactive oxygen species (ROS) and the tonicity-responsive enhancer binding protein (TonEBP) in NIH3T3 mouse fibroblasts during acute and long-term (4 h) exposure to low-sodium/ hypo-osmotic stress. Taurine influx is reduced following reduction in osmolarity, keeping the extracellular $\mathrm{Na}^{+}$ concentration constant. TonEBP activity is unaltered, whereas TauT transcription as well as TauT activity are significantly reduced under hypo-osmotic conditions. In contrast, TonEBP activity and TauT transcription are significantly increased following hyperosmotic exposure. Swelling-induced ROS production in NIH3T3 fibroblasts is generated by NOX4 and by increasing total ROS, by either exogenous application of $\mathrm{H}_{2} \mathrm{O}_{2}$ or overexpressing NOX4, we demonstrate that TonEBP activity and taurine influx are regulated negatively by ROS under hypo-osmotic, lowsodium conditions, whereas the TauT mRNA level is unaffected. Acute exposure to ROS reduces taurine uptake as a result of modulated TauT transport kinetics. Thus, swelling-induced ROS production could account for the reduced taurine uptake under low-sodium/hypo-osmotic conditions by direct modulation of TauT.
\end{abstract}

Electronic supplementary material The online version of this article (doi:10.1007/s00232-012-9416-8) contains supplementary material, which is available to authorized users.

D. B. Hansen - M. B. Friis - E. K. Hoffmann .

I. H. Lambert $(\square)$

Department of Biology, Section of Cellular and Developmental

Biology, University of Copenhagen, The August Krogh

Building, Universitetsparken 13, 2100 Copenhagen $\varnothing$, Denmark

e-mail: ihlambert@bio.ku.dk
Keywords NADPH oxidase - Hyponatremia . Osmolyte transport $\cdot$ Hypo-osmolal

\section{Introduction}

The ability to restore cell volume following osmotic perturbation is pivotal for cell function, and we have recently reviewed the intracellular signaling events evoked by cell swelling and cell shrinkage, as well as the biophysical and pharmacological characteristics of volume-sensitive transporters for organic and inorganic osmolytes (Hoffmann et al. 2009; Lambert et al. 2008). Mammalian cells restore their cell volume following osmotic perturbation; i.e., $\mathrm{KCl}$, organic osmolytes (amino acids/sugars), and water are released to or taken up from the extracellular compartment following cell swelling and cell shrinkage, respectively (Hoffmann et al. 2009). The organic acid taurine is quantitatively an important osmolyte in mammalian cells, and even though taurine is mainly recognized through its contribution to the cellular pool of organic osmolytes, it has in recent years turned out that taurine modulates multiple cellular functions through stabilization of membrane integrity, modulation of ion channel activity, shifts in membrane phospholipid content and, hence, activity of enzymes embedded in the membrane (Jong et al. 2010) or elimination of reactive oxygen species (ROS) and thereby limitation in lipid peroxidation (Goodman et al. 2009). Taurine is taken up from the extracellular compartment via the $\mathrm{Na}^{+}$-dependent taurine transporter TauT and released via a volume-sensitive leak pathway which is permeable to a range of organic osmolytes (Lambert and Hansen 2011; Hall et al. 1996; Lambert 2004). Expression of TauT is regulated by p53, c-Jun, WT1 (Wilms tumor gene 1) and TonEBP (Chesney et al. 2010; Lambert 2004), whereas 
TauT activity is acutely controlled through direct phosphorylation/dephosphorylation of TauT and/or a regulator of TauT (Hansen et al. 2011; Jacobsen et al. 2008; Voss et al. 2004; Lambert 2004). The volume-sensitive leak pathway has not been cloned but is often referred to as the volume-sensitive organic anion channel (VSOAC) (Hansen et al. 2011; Lambert 2004).

ROS in limited quantities are considered essential second messengers, whereas ROS in larger quantities become harmful to cell function and cause cell damage and cell death. ROS production increases following osmotic cell swelling (Supplementary Fig. 2) (Diaz-Elizondo et al. 2006; Friis et al. 2008; Lambert 2003; Varela et al. 2004; Ørtenblad et al. 2003; Hansen et al. 2011) as well as osmotic cell shrinkage (Zhou et al. 2006; Yang et al. 2005; Eisner et al. 2006), and it has previously been shown that ROS potentiate the swelling-induced taurine release, presumably through inactivation of protein tyrosine phosphatases and, hence, an increase in the phosphorylation of tyrosine residues of enzymes involved in the activation of the volume-sensitive taurine transporter or the transporter itself (Hansen et al. 2011; Lambert 2003). It appears that NADPH oxidases constitute the catalytic core for ROS production under hypo-osmotic conditions (Friis et al. 2008), whereas ROS under hyperosmotic conditions are of mitochondrial origin (Zhou et al. 2006). Hyperosmotically induced transcription of TauT is under the control of the tonicity-responsive enhancer binding protein (TonEBP). TonEBP is transactivated by ROS under hyperosmotic conditions (Zhou et al. 2006), whereas TonEBP mRNA is reduced and TonEBP retained in the cytoplasm under hypo-osmotic conditions (Woo et al. 2000).

Hyponatremia involves several clinical conditions that affect as much as $22 \%$ of hospitalized patients (see Loh and Verbalis 2008). Hyponatremia results in decreased sodium plasma levels from approximately 150 to $<135 \mathrm{mM}$ and is often associated with hypo-osmolarity caused by excessive renal water retention (Wakil et al. 2011; Upadhyay and Gormley 2011). Hyponatremia and generally cell swelling have been associated with increased oxidative stress (Barsony et al. 2011; Haussinger and Schliess 2008; Friis et al. 2008). Previous studies have demonstrated depletion of organic osmolytes, e.g., the brain taurine pool being reduced to $17 \%$ following chronic hyponatremia (Clark et al. 1996; Massieu et al. 2004). We initiated the present work to test whether hyponatremic/swelling-induced ROS production, besides initial potentiation of the swellinginduced taurine release, would modulate TauT activity directly or indirectly through TonEBP activity and TauT transcription, altering taurine uptake following hypoosmotic hyponatremic exposure.

\section{Materials and Methods}

\section{Cell Culture}

NIH3T3 fibroblasts were grown at $37^{\circ} \mathrm{C}, 5 \% \mathrm{CO}_{2}$ in $75 \mathrm{~cm}^{2}$ tissue culture flasks (Cellstar; Greiner Bio-One, Frickenhausen, Germany) in DMEM (335 mOsm) supplemented with $10 \%$ fetal bovine serum (FBS) and $1 \%$ penicillin/streptomycin. Cells were subcultured every 3-4 days using $0.25 \%$ trypsin in phosphate-buffered saline (PBS) containing $137 \mathrm{mM} \mathrm{NaCl}, \quad 2.6 \mathrm{mM} \quad \mathrm{KCl}, \quad 6.5 \mathrm{mM}$ $\mathrm{Na}_{2} \mathrm{HPO}_{4}$, and $1.5 \mathrm{mM} \mathrm{KH} \mathrm{PO}_{4}$. Penicillin, streptomycin, Dulbecco's modified Eagle medium (DMEM), fetal calf serum and trypsin were from Invitrogen (Naerum, Denmark).

Media

\section{Media for Taurine Influx and Estimation of ROS}

iso-osmotic DMEM (335 mOsm) contained (in $\mathrm{mM}$ ) 1.4 $\mathrm{CaCl}_{2}, 0.4 \mathrm{MgSO}_{4}, 5.4 \mathrm{KCl}, 44 \mathrm{NaHCO}_{3}, 110 \mathrm{NaCl}, 0.79$ $\mathrm{NaH}_{2} \mathrm{PO}_{4}$, and 25 D-glucose supplemented with $2 \mathrm{ml}$ amino acid solution (Sigma R7131; Sigma, St. Louis, MO) per liter. Low $\mathrm{Na}^{+}$hypo-osmotic DMEM (200 mOsm) was obtained by reduction of $\mathrm{NaCl}$ to $34 \mathrm{mM}$. Low $\mathrm{Na}^{+}$isoosmotic DMEM (335 mOsm) was obtained from the low $\mathrm{Na}^{+}$hypo-osmotic DMEM by supplementation with $0.85 \mathrm{mmol}$ sucrose per millimole reduction in $\mathrm{NaCl}$ $(21.8 \mathrm{~g} / \mathrm{l})$ (Hoffmann and Lambert 1983). Iso-osmotic $\mathrm{NaCl}$ Ringer (335 mOsm) contained (in $\mathrm{mM}$ ) $158 \mathrm{NaCl}, 5$ $\mathrm{KCl}, 1 \mathrm{Na}_{2} \mathrm{HPO}_{4}, 1 \mathrm{CaCl}_{2}, 0.1 \mathrm{MgSO}_{4}$, and $10 \operatorname{HEPES}(N$ 2-hydroxyethyl piperazine- $N^{\prime}$-2-ethanesulfonic acid). Low $\mathrm{Na}^{+}$hypo-osmotic $\mathrm{NaCl}$ Ringer (200 mOsm) was prepared by reduction of the $\mathrm{NaCl}$ concentration in the iso-osmotic $\mathrm{NaCl}$ medium to $91 \mathrm{mM}$. Low $\mathrm{Na}^{+}$iso-osmotic $\mathrm{NaCl}$ Ringer (335 mOsm) was prepared from low $\mathrm{Na}^{+}$hypoosmotic $\mathrm{NaCl}$ Ringer by supplementation with sucrose as described above for DMEM. Ringer for $\mathrm{Na}^{+}$kinetic experiments was prepared by substituting $N$-methyl-Dglucamine for $\mathrm{Na}^{+}$.

\section{Media for TonEBP/mRNA Assays}

Hypo-osmotic DMEM (200 mOsm) and hyperosmotic DMEM (500 mOsm) were obtained by dilution of DMEM (iso-osmotic, Invitrogen) with buffered water $(5 \mathrm{mM}$ HEPES) and addition of $80 \mathrm{mM} \mathrm{NaCl}$, respectively. All media were supplemented with $10 \%$ FBS and $1 \%$ penicillin/streptomycin. 


\section{Taurine Influx}

NIH3T3 cells were grown to $80 \%$ confluence in six-well polyethylene dishes $\left(9.6 \mathrm{~cm}^{2} /\right.$ well). Influx was estimated in cells preincubated for $4 \mathrm{~h}$ with the indicated DMEM medium or exposed acutely to the indicated $\mathrm{NaCl}$ Ringer. Prior to influx, cells were washed two times by gentle aspiration/addition of $600 \mu \mathrm{l}$ of the respective medium/ Ringer. ${ }^{3} \mathrm{H}$-taurine (Amersham, Aylesbury, UK; $629 \mathrm{GBq} /$ mmol) was added to cells in well 1.5 at $0,3,6,9$, and $12 \mathrm{~min}$, respectively (final taurine concentration $4.5 \mathrm{nM}$ ). At 15 min taurine uptake was terminated by removal of the extracellular medium, rapid addition/aspiration of $1 \mathrm{ml}$ icecold $\mathrm{MgCl}_{2}(115 \mathrm{mM})$, followed by cell lysis with $200 \mu \mathrm{l}$ $96 \%$ ethanol. The ethanol was blown off and the cellular ${ }^{3} \mathrm{H}$-taurine extracted by addition of $600 \mu \mathrm{l} \quad \mathrm{ddH}_{2} \mathrm{O}$ (30 min), which was transferred to a scintillation vial for estimation of ${ }^{3} \mathrm{H}$ activity ( $\beta$-scintillation counting, Ultima $\operatorname{Gold}^{\mathrm{TM}}$; Perkin-Elmer, Waltham, MA). Each well was washed twice with $\mathrm{ddH}_{2} \mathrm{O}$. The total ${ }^{3} \mathrm{H}$-taurine (cpm) taken up by the cells at a given time point was in each case estimated as the sum of ${ }^{3} \mathrm{H}$ activity in the cell extract and water washouts. Uptake (cycles per minute in each well) was converted to nanomoles per gram of protein using the extracellular specific activity and the protein content (milligrams of protein per well). The latter was estimated in the sixth well by the Lowry et al. (1951) method using BSA as standard. TauT affinity for $\mathrm{Na}^{+}$, maximal transport rate and $\mathrm{Na}^{+}$:taurine stoichiometry were estimated by fitting taurine uptake at various $\mathrm{Na}^{+}$concentrations in $\mathrm{N}$ methyl-D-glucamine chloride to a Hill-type equation as previously described (Hansen et al. 2011).

\section{TonEBP Activity—Luciferase Assay}

The -1233-1105 TonEBP-luciferase plasmid (-1233-1105) and the -1233-1105 TonEBP-luciferase mutant plasmid (-1233-1105 M) were kind gifts from Dr. J. D. Ferraris (National Institutes of Health, Bethesda, MD). The constructs were made as outlined (Trama et al. 2000; Zhou et al. 2005). Briefly, the -1233-1105 construct contains the binding motif for TonEBP, fused upstream to the luciferase gene, whereas the mutant has a nonfunctional binding motif. The constructs were transformed into DH10 $\alpha$-competent cells and subsequently isolated using E.Z.N.A Fastfilter Midi Kit (Omega Bio-Tek, Norcross, GA; cat. no. D690503). NIH3T3 cells were grown to 50\% confluence in a six-well dish prior to transfection. Transient transfection was performed using Lipofectamine 2000 (Invitrogen, cat. no. 11668-027) according to the manufacturer's instructions. Briefly, $1 \mu \mathrm{g}$ of plasmid was mixed with $5 \mu \mathrm{l} \mathrm{Lipo-}$ fectamine 2000 and $200 \mu \mathrm{l}$ serum-free DMEM without penicillin/streptomycin and left at room temperature for
30 min. The cells in one well of the six-well dish were incubated in $1.8 \mathrm{ml}$ serum-free DMEM without penicillin/ streptomycin, and $200 \mu \mathrm{l}$ transfection solution was added. The transfection medium was substituted with $2 \mathrm{ml}$ of DMEM containing serum $2.5 \mathrm{~h}$ later. Cells were transfected $48 \mathrm{~h}$ before experimental use.

All luciferase measurements were performed following $4 \mathrm{~h}$ incubation in iso-osmotic, hyperosmotic, or hypoosmotic DMEM. Transfected cells (-1233-1105) were lysed in $120 \mu \mathrm{l}$ cell culture lysis buffer (Sigma, cat. no. C-4707) and left for $15 \mathrm{~min}$ at room temperature. Cell debris was removed and protein content estimated according to the principles of the Lowry et al. (1951) method. Luciferin assay reagent $(100 \mu \mathrm{l}$; luciferase assay buffer plus luciferase assay substrate; Promega, Madison, WI; cat. no. E1501) was added to $20 \mu \mathrm{l}$ cell lysates and the luciferase activity estimated with a RamCon (Birkerod, Denmark) Fluostar Optima plate reader. Luminescence was normalized by background subtraction (-1233-1105 Mtransfected cells) and calculated relative to the amount of protein in the sample.

\section{TauT $m R N A-q P C R$}

NIH3T3 fibroblasts were grown to $70-80 \%$ confluence in tissue culture flasks $\left(75 \mathrm{~cm}^{2}\right)$. Cells were washed once in PBS, trypsinized and spun down $(600 \times g)$ and total mRNA was isolated according to the manufacturer's instructions, using the GenElute Mammalian Total RNA miniprep kit (Sigma). Total mRNA (1,500 ng) was used for cDNA synthesis using random nonamers (Sigma) and Superscript II avian reverse transcriptase (Invitrogen). cDNA was synthesized under the following conditions: $500 \mathrm{nM}$ dNTP (each) and 1,500 ng total mRNA were mixed with $2.5 \mu \mathrm{M}$ random nonamers, incubated for $10 \mathrm{~min}$ at $25^{\circ} \mathrm{C}$, heated to $65^{\circ} \mathrm{C}$ for $10 \mathrm{~min}$ and finally transferred to ice. Reaction buffer, 200 units Superscript II (Invitrogen) and $10 \mu \mathrm{M}$ dithiothreitol (DTT) were added to the sample, which was incubated at $25^{\circ} \mathrm{C}$ for $10 \mathrm{~min}, 42^{\circ} \mathrm{C}$ for $50 \mathrm{~min}$ and finally $72^{\circ} \mathrm{C}$ for $10 \mathrm{~min}$. Following incubations, samples were transferred to ice.

qPCR was performed using the Brilliant $\mathrm{SYBR}^{\circledR}$ green qPCR Master Mix (Agilent, Palo Alto, CA). Triplet measurements of TauT and $\beta$-actin expression were performed on each sample. Briefly, $25 \mu$ reaction mixtures were made containing $112.5 \mathrm{ng}$ cDNA, $1 \times$ master mix, $30 \mathrm{nM}$ reference dye and $100 \mathrm{nM}$ primer mix (TauT: forward $5^{\prime}$-ATCCTGGGCTTCATGGCACAAG- $3^{\prime}$, reverse $5^{\prime}$-AT AGACCAAAAGGTGGGCAGCG- $3^{\prime} ; \beta$-actin: forward $5^{\prime}$ AGAGCTATGAGCTGCCTGAC- $3^{\prime}$, reverse $5^{\prime}$-GGATGC CACAGGATTCCATAC-3'). qPCR was performed under the following conditions: $10 \mathrm{~min}$ at $95^{\circ} \mathrm{C}$, followed by 40 cycles of $30 \mathrm{~s}$ at $95^{\circ} \mathrm{C}, 1 \mathrm{~min}$ at $60^{\circ} \mathrm{C}, 1 \mathrm{~min}$ at $72^{\circ} \mathrm{C}$ and a 
single final elongation step for $3 \mathrm{~min}$ at $72^{\circ} \mathrm{C}$. The mean $\mathrm{C}_{\mathrm{T}}$ value was calculated. TauT expression in each sample was calculated relative to $\beta$-actin expression to normalize differences in cDNA in each sample. Subsequently, values from each sample were calculated relative to the isoosmotic control.

\section{NOX4 Construct}

Total RNA was isolated from mouse kidney renal cortex, using GenElute mammalian total RNA mini prep (Sigma, cat. no. RTN70). NOX4 was cloned using the Superscript III One-step RT-PCR system with Platinum Taq High Fidelity (Invitrogen, cat. no. 12574-030) with specific NOX4 primers (forward 5'-GAGAATTCTGGCGGTGTC CTGGAGG-3', reverse 5'-GGGGTACCTCAGCTGAAG GATTCTTTATTGTATTC- $3^{\prime}$ ). An EcoRI site was incorporated at the $5^{\prime}$ end and a KpnI site at the $3^{\prime}$ end, and whole NOX4 PCR fragment was cloned into a pCMV-HA vector (Clontech, Palo Alto, CA; cat. no. 631604). The constructs were transformed into DH10 $\alpha$-competent cells and subsequently isolated using E.Z.N.A Fastfilter Midi kit. The constructs were sequenced by MWG-Biotech (MiltonKeynes, UK). NIH3T3 fibroblasts were mock-transfected (transfection medium only) or transfected with the NOX4 construct using Lipofectamine 2000 (see above) or L-PEI. In the latter case, $3 \mu \mathrm{g}$ of plasmid was mixed with $150 \mathrm{mM}$ $\mathrm{NaCl}$ to a final volume of $100 \mu \mathrm{l}$ and $9.6 \mu \mathrm{l}$ L-PEI was mixed with $150 \mathrm{mM} \mathrm{NaCl}$ to a final volume of $100 \mu \mathrm{l}$. The L-PEI solution was added to the plasmid solution during vortexing. The final solution was mixed for $15 \mathrm{~s}$ and left at room temperature for 20 min Growth medium was changed to $1,300 \mu \mathrm{l}$ DMEM without serum or antibiotics. Plasmid solution $(200 \mu \mathrm{l})$ was added per well dropwise. Cells were left with the plasmid solution for 3-4 h before changing medium back to DMEM with serum. Cells were left for transfection $48 \mathrm{~h}$ before experimental use.

\section{Estimation of ROS Production}

ROS production was estimated as previously described (Hansen et al. 2011). Cells grown on pretreated coverslips were preincubated in serum-free growth medium containing the ROS-sensitive fluorescent probe carboxyH2DCFDA (25 lM, 2 h). Coverslips were washed with isoosmotic $\mathrm{NaCl}$ medium and placed in iso-osmotic, hyperosmotic or hypo-osmotic $\mathrm{NaCl}$ medium. ROS was estimated at $37^{\circ} \mathrm{C}$ on a thermostatic PTI (Princeton, NJ) Ratio Master spectrophotometer using excitation and emission wavelengths of 490 and $515 \mathrm{~nm}$, respectively. ROS production was estimated from the initial increase in fluorescence from 0 to $20 \mathrm{~s}$.

\section{Western Blotting}

Cell lysates were prepared in lysis buffer (1\% SDS, $150 \mathrm{mM} \mathrm{NaCl}, 20 \mathrm{mM}$ HEPES, $1 \mathrm{mM}$ EDTA, 0.5\% Triton $\mathrm{X}-100,1 \mathrm{mM} \mathrm{NaVO}$, and $1 \%$ protease inhibitor mix). SDS-PAGE gel electrophoresis was carried out in $10 \%$ Bis-Tris gels using NuPAGE MOPS SDS running buffer (Invitrogen). Proteins were transferred to nitrocellulose membranes using NuPAGE transfer buffer (Invitrogen) and the membranes blocked in TBST $(0.01 \mathrm{M}$ Tris- $\mathrm{HCl}$, $0.15 \mathrm{M} \mathrm{NaCl}, 0.1 \%$ Tween 20, pH 7.4) containing 5\% nonfat dry milk. Proteins were probed with antibodies against NOX4 (Novus Biologicals, Littleton, CO) or histone H3 (Santa Cruz Biotechnology, Santa Cruz, CA). Protein-antibody complexes were visualized using BCIP/ NBT (KPL, Gaithersburg, MD).

\section{MTT Assay-Cell Viability}

The MTT calorimetric assay was used to estimate the ability of cells to convert the yellow soluble tetrazolium salt 3-(4,5dimethylthiazol-2-yl)-2,5-diphenyltetrazolium bromide (MTT) into a blue insoluble formazan precipitate. Cells were seeded in 96-well microplates $\left(16 \times 10^{3}\right.$ in $200 \mu \mathrm{l}$ medium $)$ and incubated overnight $\left(37^{\circ} \mathrm{C}, 5 \% \mathrm{CO}_{2}\right) . \mathrm{H}_{2} \mathrm{O}_{2}$ was added, and cells were incubated for $4 \mathrm{~h}$. The MTT solution $(5 \mathrm{mg} / \mathrm{ml}$ sterilized PBS) was added ( $25 \mu \mathrm{l} /$ well) and the plate incubated $\left(37^{\circ} \mathrm{C}, 5 \% \mathrm{CO}_{2}\right)$ for $3 \mathrm{~h}$. One hundred microliters of SDS- $\mathrm{HCl}$ solution ( $5 \mathrm{ml} 0.01 \mathrm{M} \mathrm{HCl}, 0.5 \mathrm{~g} \mathrm{SDS}$ ) was added to each well and mixed to lyse the cells and solubilize the colored formazan crystals. Samples were measured at $570 \mathrm{~nm}$ using a FLUOstar OPTIMA 96-well microplate plate reader (BMG Lab Technologies, Offenburg, Germany). Data are reported in terms of relative cell viability compared to control cells with no $\mathrm{H}_{2} \mathrm{O}_{2}$. Absorbance values were assumed to be directly proportional to the number of viable cells. Each experiment was performed in triplicate.

\section{Statistics}

All data are presented either as individual experiments or as mean values \pm standard error of the mean (SEM). Statistical evaluation is based on two-way ANOVA or a Student's $t$-test (specified in legends).

\section{Results}

Taurine Uptake is Reduced by Osmotic Cell Swelling per se

Taurine uptake in NIH3T3 mouse fibroblasts was previously shown to be totally $\mathrm{Na}^{+}$-dependent and eliminated in 

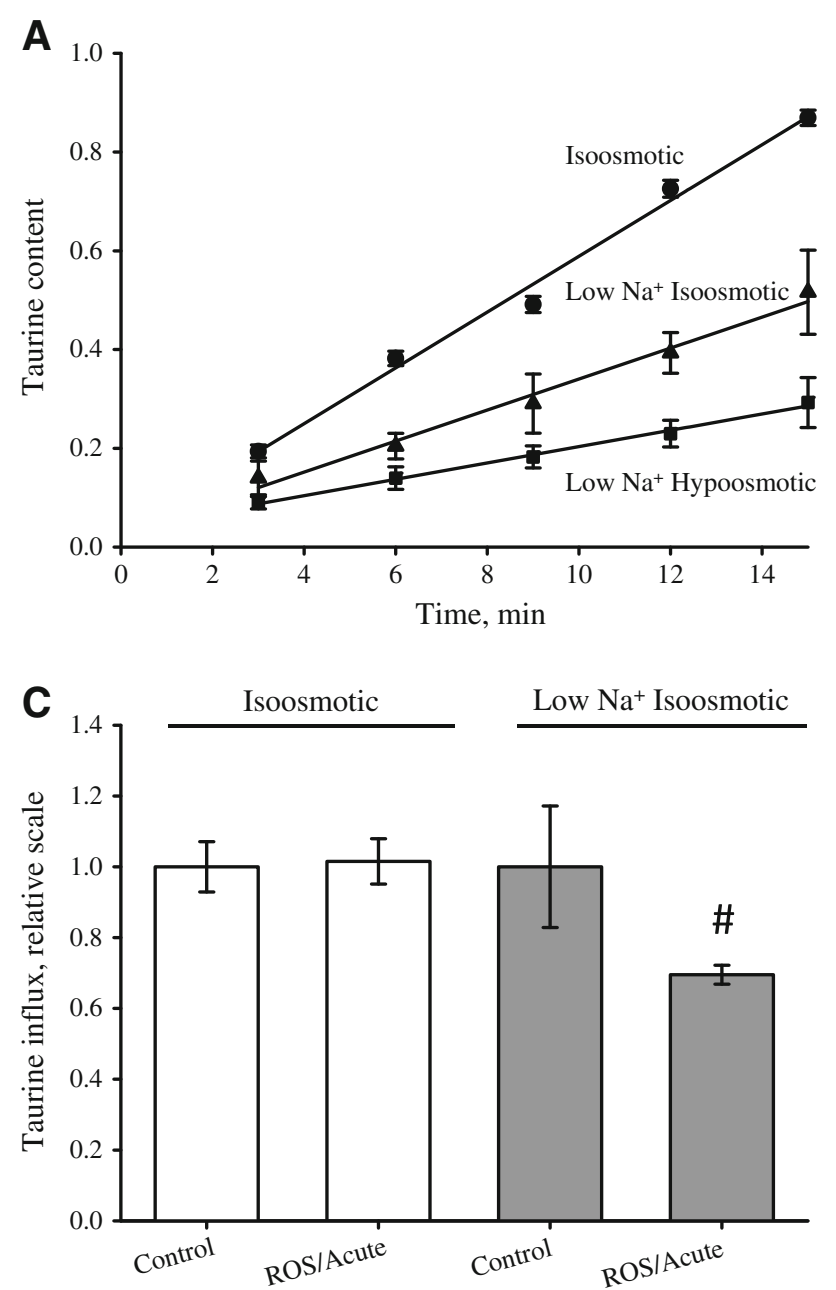

Fig. 1 The reduction in taurine uptake following hypo-osmotic exposure is independent of NOX4 activity. Taurine uptake (nmol g protein $^{-1}$ ) was estimated by the tracer technique in NIH3T3 cells exposed to either $4 \mathrm{~h}$ iso-osmotic DMEM, low $\mathrm{Na}^{+}$hypo-osmotic DMEM (200 mOsm) and low $\mathrm{Na}^{+}$iso-osmotic DMEM (335 mOsm, adjusted to osmolarity by addition of sucrose) or acutely (Acute) to iso-osmotic $\mathrm{NaCl}$, low $\mathrm{Na}^{+}$hypo-osmotic $\mathrm{NaCl}$ and low $\mathrm{Na}^{+}$isoosmotic $\mathrm{NaCl}$ (335 mOsm, adjusted to osmolarity by addition of sucrose), as described in Materials and Methods. Taurine influx (nmol g protein ${ }^{-1} \min ^{-1}$ ) was estimated by linear regression of taurine uptake within $15 \mathrm{~min}$. a Taurine uptake following $4 \mathrm{~h}$ incubation in the respective DMEM solutions. Data represent three sets of paired experiments. b Taurine influx ( $4 \mathrm{~h}$ and acute) in cells exposed for $4 \mathrm{~h}$ to the DMEM solutions $(4 \mathrm{~h})$ or acutely to the $\mathrm{NaCl}$ medium. Absolute values for controls are $0.056 \pm 0.002 \mathrm{nmol} \mathrm{g}$ protein $^{-1} \mathrm{~min}^{-1}(4 \mathrm{~h}, n=3)$ and $0.222 \pm 0.019 \mathrm{nmol} \mathrm{g}$ protein $^{-1}$ $\min ^{-1}$ (acute, $n=4$ ). Significance was determined using two-way ANOVA with Bonferroni post test, comparing treatments within the acute and $4 \mathrm{~h}$ groups, respectively. c Taurine influx in cells exposed

the presence of the taurine analog $\beta$-alanine (Voss et al. 2004), indicating that taurine uptake in the fibroblasts is mediated by TauT. From Fig. 1a, b it is seen that reduction in the total extracellular $\mathrm{Na}^{+}$concentration from 150 to $80 \mathrm{mM}$ for $4 \mathrm{~h}$, keeping osmolarity constant with sucrose, results in a significant reduction in the taurine influx in
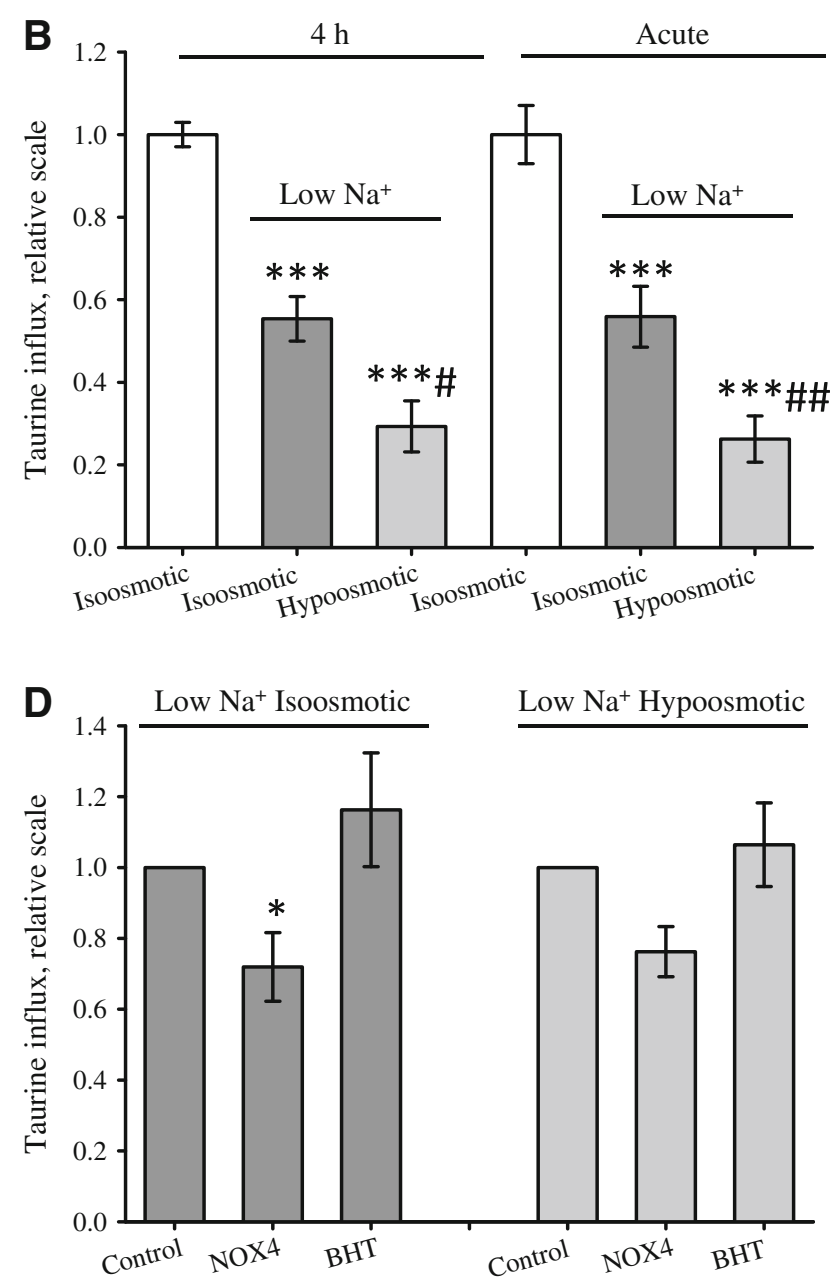

acutely to iso-osmotic and low $\mathrm{Na}^{+}$iso-osmotic $\mathrm{NaCl}$ with or without acute exposure to $0.5 \mathrm{mM} \mathrm{H} \mathrm{O}_{2}$. Absolute values for controls are $0.230 \pm 0.016 \mathrm{nmol} \mathrm{g}$ protein ${ }^{-1} \min ^{-1}$ (iso-osmotic, $n=3$ ) and $0.089 \pm 0.015 \mathrm{nmol} \mathrm{g}$ protein ${ }^{-1} \min ^{-1}$ (low $\mathrm{Na}^{+}$iso-osmotic, $n=3$ ). Significance was determined with Student's $t$-test (paired, one-sided) comparing influx with and without ROS/acute with the respective control. d Taurine influx estimated in cells acutely exposed to low $\mathrm{Na}^{+}$iso-osmotic or low $\mathrm{Na}^{+}$hypo-osmotic $\mathrm{NaCl}$. NOX4 overexpression was carried out as described in Materials and Methods. BHT $(0.5 \mathrm{mM})$ was present during the influx experiments. Statistical evaluation by two-way ANOVA with Bonferroni post test comparing influx from each treatment with the respective control; e.g., BHT-treated cells were compared with untreated, whereas NOX4-overexpressing cells were compared with mock-treated cells under iso-osmotic and hypo-osmotic conditions. All values are given relative to the respective control \pm SEM. $* P<0.05$, $* * P<0.01$, $* * * P<0.001$ compared to the respective control; ${ }^{\#} P<0.05$, ${ }^{\# \#} P<0.01$ compared to low $\mathrm{Na}^{+}$iso-osmotic

NIH3T3 cells to $56 \%$ of the iso-osmotic value (compare "iso-osmotic" to "low $\mathrm{Na}^{+}$iso-osmotic"). From Fig. 1a, b it is also seen that reduction in the extracellular osmolarity from 335 to $200 \mathrm{mOsm}$, keeping the extracellular $\mathrm{Na}^{+}$ concentration constant at $80 \mathrm{mM}$, leads to an additional $50 \%$ reduction in taurine uptake (compare "low $\mathrm{Na}^{+}$ 
iso-osmotic" to "low $\mathrm{Na}^{+}$hypo-osmotic"). Hence, TauT activity is reduced by $4 \mathrm{~h}$ exposure to hypo-osmotic conditions due to reduction in the extracellular $\mathrm{Na}^{+}$concentration as well as reduction in the extracellular osmolarity, i.e., osmotic cell swelling. This is similar to observations in Ehrlich ascites tumor cells (Hoffmann and Lambert 1983). To test whether reduced expression or membrane localization of TauT is responsible for the decreased taurine uptake under long-term hypo-osmotic conditions (4 h), we compared taurine uptake in cells exposed to $4 \mathrm{~h}$ reduction in the extracellular osmolarity with cells exposed acutely to hypo-osmotic conditions. From Fig. 1b it is seen that taurine uptake is reduced to the same extent following $4 \mathrm{~h}$ and acute reduction in the extracellular $\mathrm{Na}^{+}$concentration (compare dark gray bars at $4 \mathrm{~h}$ and acute) and in extracellular osmolarity (compare light gray bars at $4 \mathrm{~h}$ and acute). As acute and $4 \mathrm{~h}$ reduction in $\mathrm{Na}^{+}$and osmolarity give the same reduction in influx, it is suggested that the reduction in taurine uptake is most likely caused by direct inhibition of TauT. Similarly, it was previously shown in Ehrlich ascites cells that the regulation of the activity of another osmoregulatory transporter, $\mathrm{NKCC} 1$, by changes in osmolarity is not related to the number of transport molecules present in the membrane (Hoffmann et al. 1986).

ROS Reduce Taurine Uptake under Conditions with Low Extracellular $\mathrm{Na}^{+}$

Protein phosphorylation is modulated by ROS as protein phosphatases contain a redox-sensitive cysteine group in the catalytic site, rendering them inactive when oxidized by otherwise weak oxidants, such as $\mathrm{H}_{2} \mathrm{O}_{2}$ (Sommer et al. 2002; Meng et al. 2002; Wright et al. 2009; Barchowsky et al. 1995; Lee et al. 1998). ROS production in NIH3T3 cells is increased under hyperosmotic (Supplementary Fig. 1) as well as hypo-osmotic (Supplementary Fig. 2) conditions, and we speculated whether the reduced taurine uptake following hypo-osmotic cell swelling (Fig. 1b) reflects a ROS-induced shift in TauT's $\mathrm{Na}^{+}$sensitivity. From Supplementary Fig. $3 \mathrm{a}$ and Fig. $1 \mathrm{c}$ it is seen that acute exposure to $0.5 \mathrm{mM} \mathrm{H}_{2} \mathrm{O}_{2}$ has no detectable effect on taurine uptake under either hyperosmotic or iso-osmotic conditions, respectively, whereas $0.5 \mathrm{mM} \mathrm{H}_{2} \mathrm{O}_{2}$ results in a significant reduction in taurine influx under iso-osmotic conditions with low extracellular $\mathrm{Na}^{+}$concentration. It is emphasized that the effect of ROS in the latter case was tested in a medium with low $\mathrm{Na}^{+}$concentration, which was supplemented to isotonicity with sucrose in order to avoid taurine influx via the swelling-induced and ROS-sensitive taurine release pathway (Hansen et al. 2011; Lambert 2007). Exposure to $2 \mathrm{mM} \mathrm{H}_{2} \mathrm{O}_{2}$ was previously reported to reduce taurine uptake in NIH3T3 cells under iso-osmotic conditions (Voss et al. 2004). However, long-term exposure $(4 \mathrm{~h})$ to $0.5 \mathrm{mM} \mathrm{H}_{2} \mathrm{O}_{2}$ is accompanied by a reduction in taurine uptake as well as cell survival; i.e., acute exposure to a high dose or long-term exposure to a low dose of $\mathrm{H}_{2} \mathrm{O}_{2}$ is likely to kill NIH3T3 cells (Supplementary Fig. 3b).

Kinetic analysis of taurine uptake versus the extracellular $\mathrm{Na}^{+}$concentration (medium supplemented to isotonicity with $\mathrm{NMDG}$ ) revealed that acute exposure to $0.5 \mathrm{mM} \mathrm{H} \mathrm{H}_{2} \mathrm{O}_{2}$ increased the $\mathrm{Na}^{+}$:taurine stoichiometry significantly by $17 \pm 7 \%$ (control $1.93 \pm 0.14, \mathrm{H}_{2} \mathrm{O}_{2}$ treated $2.24 \pm 0.06, n=4)$, whereas it had no significant effect on the TauT affinity for $\mathrm{Na}^{+}$(control $81 \pm 13 \mathrm{mM}$, $\mathrm{H}_{2} \mathrm{O}_{2}$-treated $72 \pm 2 \mathrm{mM}, n=4$ ) or the maximal transport rate $\left(\mathrm{H}_{2} \mathrm{O}_{2}\right.$ relative to control $\left.0.94 \pm 0.11, n=4\right)$. ROS is generated by NOX4 under hypo-osmotic conditions in NIH3T3 cells (Supplementary Fig. 2), and in order to determine whether ROS produced by NOX4 could mimic the effect of acute exposure to $\mathrm{H}_{2} \mathrm{O}_{2}$ and cause a reduction in TauT taurine transport under conditions with low extracellular $\mathrm{Na}^{+}$concentration, we used ROS scavenging by butylated hydroxytoluene (BHT) (Lambert 2003) and overexpression of NOX4. There is a roughly similar reduction in taurine uptake with ROS acute and NOX4 (compare Fig. 1c, d). ROS scavenging with BHT has no significant effect on taurine uptake at low extracellular $\mathrm{Na}^{+}$ concentration under iso-osmotic and hypo-osmotic conditions (Fig. 1d), indicating that ROS scavenging has no effect on taurine uptake at low extracellular $\mathrm{Na}^{+}$ concentrations.

\section{TauT mRNA is Reduced under Hypo-Osmotic Conditions}

TauT transcription in mammalian cells is upregulated by TonEBP under hyperosmotic conditions (Miyakawa et al. 1998, 1999b), and we have previously shown that $4 \mathrm{~h}$ hyperosmotic exposure increases TauT activity in, e.g., NIH3T3 cells (Voss et al. 2004). As the effects of hypoosmotic exposure on taurine uptake appeared to be acute and independent of TauT transcription, we tested whether TonEBP activity and TauT transcription were actually unaffected by prolonged exposure to hypo-osmotic conditions. From Fig. 2 it is seen, in accordance with previous data, that exposure of NIH3T3 cells to hyperosmotic conditions results in a significant 16 -fold increase in TonEBP activity within $16 \mathrm{~h}$ (Fig. 2a) and an almost twofold increase in TauT mRNA within $4 \mathrm{~h}$ (Fig. 2b). However, TonEBP activity is unaffected by $16 \mathrm{~h}$ hypo-osmotic exposure (Fig. 2a), which is in agreement with previously demonstration of a reduction in TonEBP mRNA and retention of TonEBP in the cytoplasm under hypo-osmotic conditions (Woo et al. 2000). However, despite the unaffected TonEBP activity, TauT mRNA is reduced after $4 \mathrm{~h}$ 

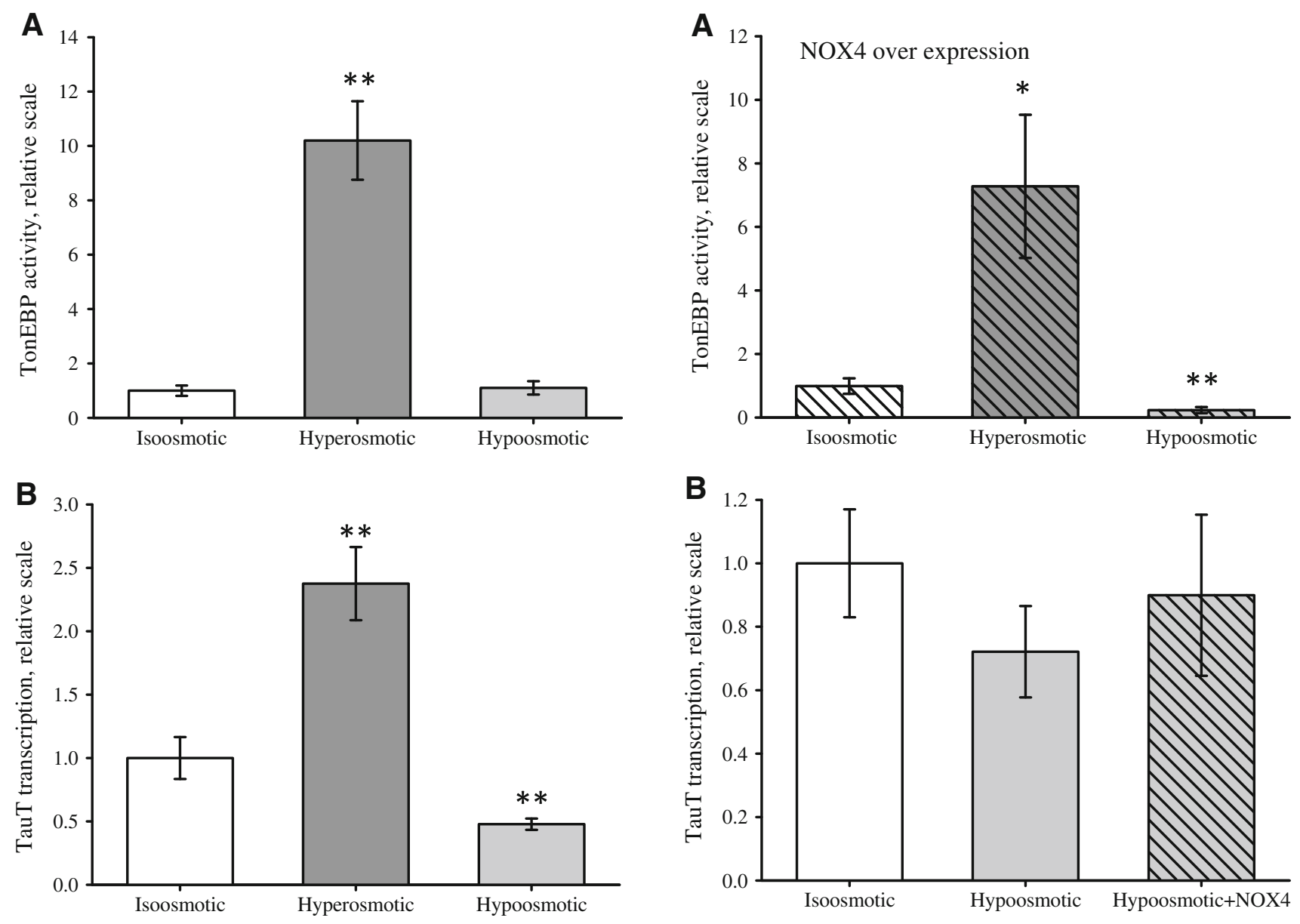

Fig. 2 Effect of long-term hyper- and hypo-osmotic conditions on TonEBP activity and TauT transcription. TonEBP activity and TauT transcription were estimated in NIH3T3 cells exposed to iso-osmotic, hyperosmotic or hypo-osmotic medium (DMEM) for 16 and $4 \mathrm{~h}$, respectively. a For estimation of TonEBP activity, cells were transfected with luciferase-plasmid and incubated with the indicated medium and luciferase activity was estimated as indicated in Materials and Methods. b TauT mRNA transcription was estimated by qPCR. cDNA was generated from mock-transfected NIH3T3 cells, and qPCR was performed using primers specific for TauT mRNA as indicated in Materials and Methods. Values are given relative to their respective iso-osmotic control \pm SEM. Data in (a) represent seven sets of paired experiments. Data in (b) represent four and five sets of paired experiments for hyperosmotic and hypo-osmotic, respectively. Statistical evaluation for (a) and (b) by Student's $t$-test (paired, onesided) comparing hyperosmotic or hypo-osmotic to iso-osmotic control, respectively. $* P<0.05, * * P<0.01$ compared to isoosmotic control

hypo-osmotic exposure (Fig. 2b). A selection of cells expressing low TauT as the cause of the observed data is most unlikely as kinetic analysis (Voss et al. 2004) revealed that there is only one population of NIH3T3 cells (one $K_{\mathrm{m}}$ value for taurine) and that the time frame of our experiments is very short. Hence, TauT mRNA levels correlate with TonEBP activity under long-term hyperosmotic conditions but not under long-term hypo-osmotic conditions.

Fig. 3 NOX4 regulates TonEBP activity, but not TauT transcription, under hypo-osmotic conditions. TonEBP activity and TauT transcription were estimated in NIH3T3 cells exposed for $4 \mathrm{~h}$ to iso-osmotic or hypo-osmotic medium (DMEM). Cells were transfected with NOX4 (hatched bars) or mock-transfected (open bars) as described in Materials and Methods. TonEBP activity and TauT mRNA were estimated as described in the legend to Fig. 2 and Materials and Methods. a TonEBP activity in NOX4-transfected cells relative to non-transfected iso-osmotic control. b TauT mRNA transcription in mock- and NOX4-transfected cells. Values are given relative to their respective iso-osmotic control $\pm \mathrm{SEM}$. Data in (a) represent seven sets of experiments. Data in (b) represent four (hypo-osmotic) and three (NOX4) sets of experiments. Statistical evaluation for (a) and (b) by Student's $t$-test (paired, one-sided) comparing hyperosmotic, hypo-osmotic or hypo-osmotic+NOX4 to the respective iso-osmotic control. Values are given relative to iso-osmotic control $\pm \mathrm{SEM}$. $* P<0.05, * * P<0.01$ compared to iso-osmotic control

Using NOX4-overexpressing cells, we tested whether ROS generated by NOX 4 could affect TonEBP activity and TauT transcription. It is seen that the increase in TonEBP activity following hypertonic exposure in NOX4-overexpressing cells is comparable to that in native cells, whereas there is a significant decrease in TonEBP activity under hypo-osmotic conditions (4 h) (Fig. 3a). The significant reduction in TonEBP activity under hypo-osmotic conditions compared to iso-osmotic conditions is taken to indicate that TonEBP is negatively regulated by excess 
ROS produced by NOX4 under hypo-osmotic conditions. From Fig. $3 b$ it is seen that TauT mRNA transcription is unaltered under hypo-osmotic conditions when overexpressing NOX4. Thus, the increased ROS availability generated from NOX4 under hypo-osmotic conditions does not seem to suppress TauT transcription via the altered TonEBP activity.

To test these results, we applied $\mathrm{ROS}\left(\mathrm{H}_{2} \mathrm{O}_{2}\right)$ and the phosphatase inhibitor vanadate and estimated TonEBP activity. Unexpectedly, we found that both ROS and vanadate reduced TonEBP activity significantly when added acutely to NIH3T3 cells preincubated under hyperosmotic conditions (16 h, $500 \mathrm{mOsm})$, i.e., immediately before lysis and estimation of luciferase activity (Supplementary Fig. 4a). $\mathrm{Mg}^{2+}$-dependent ATPases are inhibited by vanadate (Bond and Hudgins 1980; Hanocq-Quertier et al. 1988), and as the luciferase used in this assay requires $\mathrm{Mg}^{2+}$ as cosubstrate (Promega technical bulletin 281), the observed acute effect of vanadate on the TonEBP assay is most likely a result of luciferase inhibition. Thus, $\mathrm{H}_{2} \mathrm{O}_{2}$ and vanadate most likely interfere directly with luciferase activity. Furthermore, prolonged exposure to $\mathrm{H}_{2} \mathrm{O}_{2}$ $(0.5 \mathrm{mM})$ under hyperosmotic conditions results in significantly reduced TauT transcription (Supplementary Fig. 4b); this is, however, most likely an effect of the significant cell death following prolonged exposure to $\mathrm{H}_{2} \mathrm{O}_{2}$ (Supplementary Fig. 3b). The effect of $\mathrm{H}_{2} \mathrm{O}_{2}$ and vanadate on TonEBP activity and TauT transcription will therefore not be discussed further.

\section{Discussion}

Active taurine uptake in mammalian cells is fueled by the prevailing $\mathrm{Na}^{+}$gradient, and TauT activity is regulated by various protein kinases, e.g., protein kinase A (PKA) and PKC plus casein kinase 2 (CK2) (Hansen et al. 2011; Jacobsen et al. 2008; Voss et al. 2004). We find here, in agreement with previous results (Hoffmann and Lambert 1983), that osmotic cell swelling per se results in an inhibition of taurine uptake. Acute regulation of TauT often involves a shift in the maximal transport capacity $\left(V_{\max }\right)$, the substrate concentration required for half-maximal transport activity $\left(K_{\mathrm{m}}\right.$ values for taurine $\left[K_{\mathrm{m} \text { taurine }}\right]$ and $\left.\mathrm{Na}^{+}\left[K_{\mathrm{m} \mathrm{Na}}\right]\right)$ and/or the $\mathrm{Na}^{+}$:taurine transport stoichiometry (Lambert 2004). In the case of NIH3T3 fibroblasts, we recently demonstrated that phosphorylation, mediated by the constitutively active serin/threonine kinase CK2, reduces the affinity of TauT toward $\mathrm{Na}^{+}$plus the maximal transport activity and increases the $\mathrm{Na}^{+}$:taurine stoichiometry and that the effect of CK2 inhibition on TauT activity was more pronounced at an extracellular $\mathrm{Na}^{+}$concentration close to $K_{\mathrm{m} \text { Na }}$ (Hansen et al. 2011). Osmotic cell swelling is accompanied by an increase in the production of ROS in NIH3T3 mouse fibroblasts, porcine myotubes, HTC cells (liver-derived cell line), HEK293 cells, collecting duct cells and neonatal rat cardiomyocytes (Zhou et al. 2006; DiazElizondo et al. 2006; Friis et al. 2008; Lambert 2003; Varela et al. 2004; Ørtenblad et al. 2003; Hansen et al. 2011); and we have recently shown that a NOX4/p22phox complex constitutes the catalytic core of the volume-sensitive NADPH oxidase in NIH3T3 fibroblasts (Friis et al. 2008). Furthermore, NADPH-oxidase activity has been assigned a role in the increased ROS production during hyponatremia (Haussinger and Schliess 2008). It thus seemed likely that taurine uptake could be modulated by ROS following hypoosmotic/hyponatremic conditions.

The present data indicate that acute exposure to $0.5 \mathrm{mM}$ $\mathrm{H}_{2} \mathrm{O}_{2}$ under iso-osmotic conditions has no detectable effect on taurine uptake at standard extracellular $\mathrm{Na}^{+}$concentration, whereas $\mathrm{H}_{2} \mathrm{O}_{2}$ reduces uptake under conditions with low extracellular $\mathrm{Na}^{+}$(Fig. 1c). NOX4 overexpression increases the swelling-induced ROS production in NIH3T3 cells and, similar to $\mathrm{H}_{2} \mathrm{O}_{2}$ exposure, appears to reduce taurine uptake under conditions with low extracellular $\mathrm{Na}^{+}$concentration (Fig. 1c, d). We also find that the $\mathrm{Na}^{+}$:taurine transport stoichiometry is increased by addition of $0.5 \mathrm{mM} \mathrm{H}_{2} \mathrm{O}_{2}$; i.e., lower concentrations of $\mathrm{Na}^{+}$are required for equivalent taurine uptake following addition of $\mathrm{H}_{2} \mathrm{O}_{2}$ as long as the concentration of sodium is above $K_{\mathrm{m}}$ $\mathrm{Na}$. Increased availability of ROS under hypo-osmotic conditions can partly explain the observed reduction in taurine uptake when the extracellular $\mathrm{Na}^{+}$concentration is reduced. However, the increased $\mathrm{Na}^{+}$:taurine stoichiometry by ROS will only reduce the uptake of taurine at $\mathrm{Na}^{+}$ concentrations below $K_{\mathrm{m} \mathrm{Na}}$. As the $\mathrm{Na}^{+}$concentration is not reduced below $K_{\mathrm{m} \mathrm{Na}}$ even under severe hyponatremia, this effect is probably not pathophysiologically relevant.

\section{ROS—TonEBP—Tonicity Sensitivity}

Long-term regulation in NIH3T3 cells, following continuous exposure to hyperosmotic stress or substrate (taurine), relies on the transcriptional modulation of the gene encoding TauT (Voss et al. 2004). The transcriptional increase in the expression of the $\mathrm{Na}^{+}$-dependent co-transporters, sodium/myo-inositol co-transporter (SMIT), sodium/chloride/betaine co-transporter (BGT1), and TauT is facilitated by the $c i s$-element tonicity-response enhancer (TonE) (Miyakawa et al. 1998; Rim et al. 1998), which is regulated by TonEBP (Han et al. 2006; Ito et al. 2004; Jeon et al. 2006; Miyakawa et al. 1999b). TonEBP plays a key role in the protection of cells from prolonged increase in the extracellular osmolarity by increasing the cellular content of osmolytes through transcription of co-transporters for organic and inorganic osmolytes (Han et al. 
2006; Ito et al. 2004; Jeon et al. 2006; Miyakawa et al. 1999a, 1999b). Mice lacking functional TonEBP $\left(\mathrm{TonEBP}^{-l-}\right.$ ) have a severe renal medulla degeneration caused by low levels of SMIT, aldose reductase and TauT expression (Lopez-Rodriguez et al. 2004). TonEBP is evenly distributed between the cytosol and nucleus under iso-osmotic conditions, whereas hyperosmolarity increases and hypo-osmolarity decreases the nuclear fraction (Woo et al. 2000; Miyakawa et al. 1999b; Cha et al. 2001; Tong et al. 2006). In accordance, hyperosmotic stress results in increased expression and activation of TonEBP (LopezRodriguez et al. 2004; Woo et al. 2002; Zhou et al. 2006; Cai et al. 2005), whereas TonEBP transcription is reduced and nuclear export accelerated during hypo-osmotic stress (Woo et al. 2000; Tong et al. 2006). TonEBP activity and nuclear translocation are regulated by serine and tyrosine phosphorylation (reviewed in Burg et al. 2007; Aramburu et al. 2006). The increased TonEBP activity following hyperosmotic exposure involves mitochondrial release of ROS (Zhou et al. 2005, 2006; Ferraris et al. 2002). In the present study we demonstrate that TonEBP activity is similarly stimulated under hyperosmotic conditions but unaffected under hypo-osmotic conditions (Fig. 2). In NOX4-overexpressing NIH3T3 cells TonEBP activity is still increased under hyperosmotic conditions, whereas TonEBP activity is significantly reduced under hypoosmotic conditions (Fig. 3).

Figure 4 summarizes data and illustrates modulation of taurine uptake by TauT in NIH3T3 cells following osmotic stress. TauT transcription is generally assumed to follow TonEBP activity. This is also the case for TauT transcription under hyperosmotic conditions (Fig. 2). However, we find that under long-term hypo-osmotic exposure the downregulation of TauT transcription is not secondary to reduced TonEBP activity as (1) TonEBP activity is unaltered whereas TauT mRNA is reduced (Fig. 2) and (2) stimulation and hindrance of TonEBP activity by increased NOX4 expression do not correlate with TauT transcription level (Fig. 3). The lack of correlation between TonEBP activity and TauT transcription under hypo-osmotic conditions could indicate that TauT transcription is dependent on other transcription factors inactivated by hypo-osmolarity. Under hyperosmotic conditions, ROS generated from the mitochondria are reported to stimulate TonEBP transactivation via a hyper-osmotically induced transactivation domain (TAD) (Zhou et al. 2006), and we hypothesize that the primary effect of ROS on TonEBP-TAD is an increased sensitivity toward tonicity. In this scenario ROS stimulate TonEBP transactivation under conditions with high extracellular ion concentrations, whereas TonEBP transactivation is further suppressed by NOX4-generated ROS under conditions with low extracellular ion concentrations. Our current hypothesis is that ROS-mediated

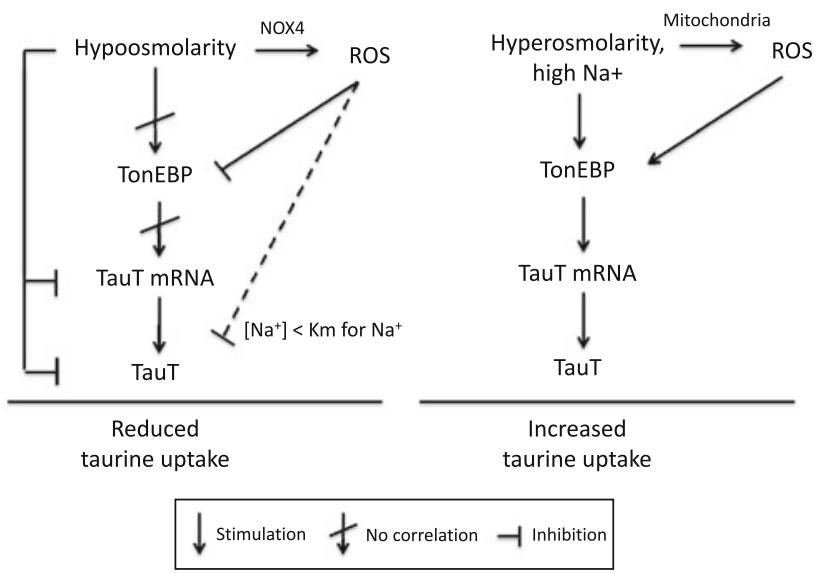

Fig. 4 Modulation of taurine uptake by TauT following osmotic stress. The model is described in the text

interference with TauT kinetics is only visible under conditions with very low $\mathrm{Na}^{+}$concentrations, i.e., concentrations significantly lower than those observed under hypoosmotic hyponatremia, but will have no effect on taurine transport under conditions with high or normal extracellular $\mathrm{Na}^{+}$concentrations. The hypo-osmotically induced reduction in TauT mRNA will reduce TauT activity following prolonged osmotic stress. The reduction in cellular taurine content following hyponatremia is probably dominated by increased taurine leak, whereas more chronic conditions can involve the reduction in TauT mRNA.

Acknowledgments The present work was supported by The Danish Natural Sciences Research Council (grants 21-04-0535, 272-07-0530, 272-08-0170, 271-08-0520). Dr. J. D. Ferraris (National Institutes of Health, Bethesda, MD) is acknowledged for donation of the -12331105 TonEBP-luciferase plasmid (-1233-1105) and the -1233-1105 TonEBP-luciferase mutant plasmid (-1233-1105 M). Tina Rødgaard is acknowledged for contributing to experiments included in Fig. 2a. The technical assistance of Dorthe Nielsen is gratefully acknowledged.

Open Access This article is distributed under the terms of the Creative Commons Attribution License which permits any use, distribution, and reproduction in any medium, provided the original author(s) and the source are credited.

\section{References}

Aramburu J, Drews-Elger K, Estrada-Gelonch A, Minguillon J, Morancho B, Santiago V, Lopez-Rodriguez C (2006) Regulation of the hypertonic stress response and other cellular functions by the Rel-like transcription factor NFAT5. Biochem Pharmacol 72:1597-1604

Barchowsky A, Munro SR, Morana SJ, Vincenti MP, Treadwell M (1995) Oxidant-sensitive and phosphorylation-dependent activation of NF-kappa B and AP-1 in endothelial cells. Am J Physiol Lung Cell Mol Physiol 269:L829-L836 
Barsony J, Sugimura Y, Verbalis JG (2011) Osteoclast response to low extracellular sodium and the mechanism of hyponatremiainduced bone loss. J Biol Chem 286:10864-10875

Bond GH, Hudgins PM (1980) Inhibition of red cell $\mathrm{Ca}^{2+}$-ATPase by vanadate. Biochim Biophys Acta 600:781-790

Burg MB, Ferraris JD, Dmitrieva NI (2007) Cellular response to hyperosmotic stresses. Physiol Rev 87:1441-1474

Cai Q, Ferraris JD, Burg MB (2005) High $\mathrm{NaCl}$ increases TonEBP/ OREBP mRNA and protein by stabilizing its mRNA. Am J Physiol Renal Physiol 289:F803-F807

Cha JH, Woo SK, Han KH, Kim YH, Handler JS, Kim J, Kwon HM (2001) Hydration status affects nuclear distribution of transcription factor tonicity responsive enhancer binding protein in rat kidney. J Am Soc Nephrol 12:2221-2230

Chesney RW, Han X, Patters AB (2010) Taurine and the renal system. J Biomed Sci 17(Suppl 1):S4

Clark EC, Thomas D, Baer J, Sterns RH (1996) Depletion of glutathione from brain cells in hyponatremia. Kidney Int 49: $470-476$

Diaz-Elizondo J, Chiong M, Rojas-Rivera D, Olea-Azar C, Kwon HM, Lavandero S (2006) Reactive oxygen species inhibit hyposmotic stress-dependent volume regulation in cultured rat cardiomyocytes. Biochem Biophys Res Commun 350: 1076-1081

Eisner V, Criollo A, Quiroga C, Olea-Azar C, Santibanez JF, Troncoso R, Chiong M, az-Araya G, Foncea R, Lavandero S (2006) Hyperosmotic stress-dependent NFkappaB activation is regulated by reactive oxygen species and IGF-1 in cultured cardiomyocytes. FEBS Lett 580:4495-4500

Ferraris JD, Williams CK, Persaud P, Zhang Z, Chen Y, Burg MB (2002) Activity of the TonEBP/OREBP transactivation domain varies directly with extracellular $\mathrm{NaCl}$ concentration. Proc Natl Acad Sci USA 99:739-744

Friis MB, Vorum KG, Lambert IH (2008) Volume-sensitive NADPH oxidase activity and taurine efflux in NIH3T3 mouse fibroblasts. Am J Physiol Cell Physiol 294:C1552-C1565

Goodman CA, Horvath D, Stathis C, Mori T, Croft K, Murphy RM, Hayes A (2009) Taurine supplementation increases skeletal muscle force production and protects muscle function during and after high-frequency in vitro stimulation. J Appl Physiol 107: 144-154

Hall JA, Kirk J, Potts JR, Rae C, Kirk K (1996) Anion channel blockers inhibit swelling-activated anion, cation, and nonelectrolyte transport in HeLa cells. Am J Physiol Cell Physiol 271:C579-C588

Han X, Patters AB, Jones DP, Zelikovic I, Chesney RW (2006) The taurine transporter: mechanisms of regulation. Acta Physiol 187:61-73

Hanocq-Quertier J, Baltus E, Schram E (1988) Bioluminescent assay of ATPase activity in embryonic material using firefly luciferase. J Biolumin Chemilumin 2:17-24

Hansen DB, Guerra B, Jacobsen JH, Lambert IH (2011) Regulation of taurine homeostasis by protein kinase CK2 in mouse fibroblasts. Amino Acids 40:1091-1106

Haussinger D, Schliess F (2008) Pathogenetic mechanisms of hepatic encephalopathy. Gut 57:1156-1165

Hoffmann EK, Lambert IH (1983) Amino acid transport and cell volume regulation in Ehrlich ascites tumour cells. J Physiol 338:613-625

Hoffmann EK, Schiodt M, Dunham P (1986) The number of chloridecation cotransport sites on Ehrlich ascites cells measured with ${ }^{3}$ H-bumetanide. Am J Physiol Cell Physiol 250:C688-C693

Hoffmann EK, Lambert IH, Pedersen SF (2009) Physiology of cell volume regulation in vertebrates. Physiol Rev 89:193-277

Ito T, Fujio Y, Hirata M, Takatani T, Matsuda T, Muraoka S, Takahashi K, Azuma J (2004) Expression of taurine transporter is regulated through the TonE (tonicity-responsive element)/ TonEBP (TonE-binding protein) pathway and contributes to cytoprotection in HepG2 cells. Biochem J 382:177-182

Jacobsen JH, Clement CA, Friis MB, Lambert IH (2008) Casein kinase 2 regulates the active uptake of the organic osmolyte taurine in NIH3T3 mouse fibroblasts. Pflugers Arch 457:327-337

Jeon US, Kim JA, Sheen MR, Kwon HM (2006) How tonicity regulates genes: story of TonEBP transcriptional activator. Acta Physiol (Oxf) 187:241-247

Jong CJ, Ito T, Mozaffari M, Azuma J, Schaffer S (2010) Effect of beta-alanine treatment on mitochondrial taurine level and 5-taurinomethyluridine content. J Biomed Sci 17(Suppl 1):S25

Lambert IH (2003) Reactive oxygen species regulate swellinginduced taurine efflux in NIH3T3 mouse fibroblasts. J Membr Biol 192:19-32

Lambert IH (2004) Regulation of the cellular content of the organic osmolyte taurine in mammalian cells. Neurochem Res 29:27-63

Lambert IH (2007) Activation and inactivation of the volumesensitive taurine leak pathway in NIH3T3 fibroblasts and Ehrlich Lettre acites cells. Am J Physiol Cell Physiol 293:C390-C400

Lambert IH, Hansen DB (2011) Regulation of taurine transport systems by protein kinase CK2 in mammalian cells. Cell Physiol Biochem 28:1099-1110

Lambert IH, Hoffmann EK, Pedersen SF (2008) Cell volume regulation: physiology and pathophysiology. Acta Physiol Scand 194:255-282

Lee SR, Kwon KS, Kim SR, Rhee SG (1998) Reversible inactivation of protein-tyrosine phosphatase 1B in A431 cells stimulated with epidermal growth factor. J Biol Chem 273:15366-15372

Loh JA, Verbalis JG (2008) Disorders of water and salt metabolism associated with pituitary disease. Endocrinol Metab Clin North Am 37:213-234

Lopez-Rodriguez C, Antos CL, Shelton JM, Richardson JA, Lin F, Novobrantseva TI, Bronson RT, Igarashi P, Rao A, Olson EN (2004) Loss of NFAT5 results in renal atrophy and lack of tonicity-responsive gene expression. Proc Natl Acad Sci USA 101:2392-2397

Lowry OH, Rosebrough NJ, Farr AL, Randall RJ (1951) Protein measurement with the folin phenol reagent. J Biol Chem 193: 265-275

Massieu L, Montiel T, Robles G, Quesada O (2004) Brain amino acids during hyponatremia in vivo: clinical observations and experimental studies. Neurochem Res 29:73-81

Meng TC, Fukada T, Tonks NK (2002) Reversible oxidation and inactivation of protein tyrosine phosphatases in vivo. Mol Cell 9:387-399

Miyakawa H, Woo SK, Chen CP, Dahl SC, Handler JS, Kwon HM (1998) Cis- and trans-acting factors regulating transcription of the $B G T 1$ gene in response to hypertonicity. Am J Physiol Renal Physiol 274:F753-F761

Miyakawa H, Rim JS, Handler JS, Kwon HM (1999a) Identification of the second tonicity-responsive enhancer for the betaine transporter (BGT1) gene. Biochim Biophys Acta 1446:359-364

Miyakawa H, Woo SK, Dahl SC, Handler JS, Kwon HM (1999b) Tonicity-responsive enhancer binding protein, a rel-like protein that stimulates transcription in response to hypertonicity. Proc Natl Acad Sci USA 96:2538-2542

Ørtenblad N, Young JF, Oksbjerg N, Nielsen JH, Lambert IH (2003) Reactive oxygen species are important mediators of taurine release from skeletal muscle cells. Am J Physiol Cell Physiol 284:C1362-C1373

Rim JS, Atta MG, Dahl SC, Berry GT, Handler JS, Kwon HM (1998) Transcription of the sodium/myo-inositol cotransporter gene is regulated by multiple tonicity-responsive enhancers spread over 50 kilobase pairs in the $5^{\prime}$-flanking region. J Biol Chem 273:20615-20621 
Sommer D, Coleman S, Swanson SA, Stemmer PM (2002) Differential susceptibilities of serine/threonine phosphatases to oxidative and nitrosative stress. Arch Biochem Biophys 404:271-278

Tong EH, Guo JJ, Huang AL, Liu H, Hu CD, Chung SS, Ko BC (2006) Regulation of nucleocytoplasmic trafficking of transcription factor OREBP/TonEBP/NFAT5. J Biol Chem 281:23870-23879

Trama J, Lu Q, Hawley RG, Ho SN (2000) The NFAT-related protein NFATL1 (TonEBP/NFAT5) is induced upon T cell activation in a calcineurin-dependent manner. J Immunol 165:4884-4894

Upadhyay UM, Gormley WB (2011) Etiology and management of hyponatremia in neurosurgical patients. J Intensive Care Med. doi: $10.1177 / 0885066610395489$

Varela D, Simon F, Riveros A, Jorgensen F, Stutzin A (2004) $\mathrm{NAD}(\mathrm{P}) \mathrm{H}$ oxidase-derived $\mathrm{H}_{2} \mathrm{O}_{2}$ signals chloride channel activation in cell volume regulation and cell proliferation. J Biol Chem 279:13301-13304

Voss JW, Pedersen SF, Christensen ST, Lambert IH (2004) Regulation of the expression and subcellular localisation of the taurine transporter TauT in mouse NIH3T3 fibroblasts. Eur J Biochem 271:4646-4658

Wakil A, Ng JM, Atkin SL (2011) Investigating hyponatraemia. BMJ 342:d1118
Woo SK, Dahl SC, Handler JS, Kwon HM (2000) Bidirectional regulation of tonicity-responsive enhancer binding protein in response to changes in tonicity. Am J Physiol Renal Physiol 278:F1006-F1012

Woo SK, Lee SD, Na KY, Park WK, Kwon HM (2002) TonEBP/ NFAT5 stimulates transcription of HSP70 in response to hypertonicity. Mol Cell Biol 22:5753-5760

Wright VP, Reiser PJ, Clanton TL (2009) Redox modulation of global phosphatase activity and protein phosphorylation in intact skeletal muscle. J Physiol 587:5767-5781

Yang T, Zhang A, Honeggar M, Kohan DE, Mizel D, Sanders K, Hoidal JR, Briggs JP, Schnermann JB (2005) Hypertonic induction of COX-2 in collecting duct cells by reactive oxygen species of mitochondrial origin. J Biol Chem 280:34966-34973

Zhou X, Ferraris JD, Cai Q, Agarwal A, Burg MB (2005) Increased reactive oxygen species contribute to high $\mathrm{NaCl}$-induced activation of the osmoregulatory transcription factor TonEBP/ OREBP. Am J Physiol Renal Physiol 289:F377-F385

Zhou X, Ferraris JD, Burg MB (2006) Mitochondrial reactive oxygen species contribute to high $\mathrm{NaCl}$-induced activation of the transcription factor TonEBP/OREBP. Am J Physiol Renal Physiol 290:F1169-F1176 